\title{
La Nueva gramática de la lengua española y las estructuras pronominales
}

\author{
José Ramón Heredia* \\ Universidad de Castilla-La Mancha, España
}

\begin{abstract}
Resumen
En este artículo nos proponemos comparar dos descripciones de las llamadas 'estructuras' o 'construcciones pronominales': a) la que se da en la Nueva gramática de la lengua española (que, sin embargo, no reconoce el concepto de 'estructura' o 'construcción pronominal') y b) la descripción alternativa derivada de nuestro propio modelo descriptivo, que nos ha servido de base a un trabajo, de índole comparativa, que aún está en progreso sobre el particular. Tras exponer ambas descripciones y llevar a cabo la comparación entre ambas, hacemos una crítica negativa de la visión académica, que, pese a lo ambicioso de su planteamiento, resulta confusa, a veces contradictoria y muy poco didáctica. Estas deficiencias son, precisamente, las que intenta superar nuestro modelo descriptivo y las que nos motivan a considerarlo más adecuado que la descripción propuesta por la Academia.
\end{abstract}

*Para correspondencia, dirigirse a: José Ramón Heredia Ranz (JoseRamon.Heredia@uclm. es), Facultad de Letras de la Universidad de Castilla-La Mancha, Avda. Camilo José Cela, s/n, 13071 Ciudad Real, España. 
Palabras clave: construcción o estructura pronominal, verbo pronominal, construcción media, estructura pronominal 'regular', estructura pronominal de incidencia léxica.

The new Grammar of the Spanish language And the PRONOMINAL STRUCTURES

\begin{abstract}
The aim of this article is to compare two different descriptions of 'pronominal structures', or 'pronominal constructions': a) that presented in the 'Nueva gramática de la lengua española' ('New grammar of the Spanish language'), which does not acknowledge the concept of 'pronominal structure', 'or pronominal construction', and b) the an alternative description deriving from our own descriptive model (on which we have founded a contrastive research on the subject still in progress). After presenting and contrasting both descriptions we make an argument against the 'academic view' because it turns out to be confusing, sometimes contradictory, and not didactic. These deficiencies are dealt with in our descriptive model, and this is the reason why we consider it more appropriate than the academic description.
\end{abstract}

Key words: pronominal structure or construction, pronominal verb, medial construction, 'regular' pronominal structure, pronominal structure with lexical incidence.

Recibido: 01/03/11. Aceptado: 04/05/11.

Decir a estas alturas que la Nueva gramática de la lengua española es una obra monumental y calificar de esfuerzo titánico el de sus autores y colaboradores no deja de ser un tópico y un aserto no demasiado original. Con todo, así lo decimos, puesto que no se puede tratar de dicha Gramática sin reconocer de entrada sus innumerables virtudes, así como la labor que viene realizando últimamente la Real Academia junto con las demás Academias de la Lengua Española. Y aunque aquí no vamos a hacer una reseña de esta obra, sino a limitarnos a uno solo de sus aspectos (que, por lo demás, no consideramos especialmente satisfactorios), justo es empezar con un elogio incondicional a este admirable registro (análisis y explicación) de la práctica totalidad del idioma español dentro y fuera de España. 
Lo que en este trabajo nos proponemos es examinar el tratamiento que da la Nueva gramática a las estructuras pronominales y compararlo con nuestro modelo descriptivo sobre el particular. Una primera discrepancia la hallamos en la no conceptualización por parte de la Academia de las estructuras o construcciones pronominales. De ello y de otras divergencias vamos a tratar a continuación empezando por dar cuenta, en un apartado introductorio, de nuestro propio modelo descriptivo.

\section{INTRODUCCIÓN}

Desde hace unos diez años venimos trabajando en un proyecto descriptivocontrastivo sobre las estructuras pronominales en español que se inicia con una descripción referida a la lengua española, a la que siguen sendos análisis contrastivos entre el español y las demás lenguas objeto de comparación, para concluir con un diccionario multilingüe de las estructuras pronominales de incidencia léxica (v. más adelante), precisamente aquellas cuya descripción requiere en última instancia un tratamiento individualizado, lexicográfico. Hay, pues, 1) descripción, 2) comparación y 3) análisis lexicográfico (con traducción multilingüe). En este trabajo, y a modo de introducción, vamos a dar cuenta sucinta de la parte descriptiva del proyecto $-\mathrm{y}$ del trabajo que pensamos publicar en breve ${ }^{1}$.

Dicha parte viene a ser, por un lado, una especie de teoría sobre la "pronominalidad" en español, y por otro, la base, el marco de referencia de las comparaciones subsiguientes, puesto que partimos de la hipótesis de que las estructuras pronominales son uno de los aspectos idiosincrásicos de la

1 En el IV Congreso de Lingüística General, celebrado en Cádiz en abril de 2000, presentábamos el proyecto Las estructuras pronominales en español: guía y análisis contrastivo (italiano, francés, alemán e inglés) (Heredia et al. 2002). El objetivo final era la elaboración de una amplia obra de referencia y de marcado carácter didáctico. En la actualidad, si bien se mantiene el proyecto como línea de investigación, el grupo de trabajo inicial se ha disuelto y, con él, su objetivo final ha pasado a ser un desiderátum, si no inviable, difícil de alcanzar a corto o medio plazo. De todos modos sí que ha habido resultados parciales de la investigación, con publicaciones, seminarios, comunicaciones a congresos, etc., que sería largo enumerar aquí. Queda, como decíamos, una línea de investigación, abierta a nuevos enfoques y nuevas lenguas (p. e., el rumano: Heredia, en prensa), y un objetivo inmediato, la publicación de un trabajo, parcialmente confeccionado: J. R. Heredia, Guía descriptivodidáctica de las estructuras pronominales en español. Bases para un diccionario multilingüe. 
lengua española, no tanto por la exclusividad del procedimiento gramatical, cuanto por el grado de desarrollo y las posibilidades expresivas que alcanza. Se trata, pues, de trazar y delimitar ese marco para la lengua española, y a partir de ahí, de llevar a cabo los análisis comparativos y las traducciones en las demás lenguas.

Para ofrecer una visión global de la materia, partimos del concepto de estructura o construcción pronominal -y no de verbo pronominal, reflexivo o reflejo. Entendemos como estructura pronominal aquel sintagma verbal que presenta alguno de los clíticos me, te, se (no variante de le-les), nos u os, en concordancia de número y persona con la forma verbal correspondiente ${ }^{2}$; esto es, en términos tradicionales, un sintagma verbal que contenga un pronombre reflexivo átono. Así, por ejemplo, Yo me lavo sería una estructura pronominal, y no lo sería en cambio Yo la lavo, que sería, simplemente, una estructura con pronombre. Las oraciones de (1) contienen asimismo estructuras pronominales (al lado de cada una figura una versión no pronominal):

(1) a. Juan se afeita a diario [/Juan afeita a su padre].

b. Juan y Pedro se odian (el uno al otro) [/Juan y Pedro odian la violencia].

c. Se necesitan soluciones [/Juan necesita soluciones].

c' Se necesita a los chicos [/Juan necesita a los chicos].

d. Juan se paró [/Juan paró a Pedro].

El autobús se paró [/Juan (el conductor) paró el autobús].

e. Juan no se entera de nada [/*Juan no entera de nada a Pedro].

f. Juan no se acordó de nada [/Juan no acordó nada con Pedro].

g. Juan se fue a Madrid [/Juan fue a Madrid].

Obviamente, estas oraciones, pese a su identidad formal (en lo que se refiere a la presencia del clítico reflejo), no transmiten el mismo tipo de contenidos, y esa diversidad semántica es la que nos permite distinguirlas entre sí, establecer distintos tipos de estructura pronominal (sin pronunciarnos aquí sobre el problema de si constituyen una sola o distintas categorías gramaticales, la conocida cuestión que se plantea en las gramáticas del

2 Es, esencialmente, la definición que da N. Cartagena (1972: 21) de construcción pronominal, designación sinónima de estructura pronominal, que se ha ido imponiendo en la terminología gramatical del español a partir sobre todo de la obra de Martín Zorraquino (1979) -Las construcciones pronominales [...]. Estructura o construcción las empleamos, aquí y en el proyecto, de forma indistinta, si bien hemos optado por la primera como término genérico e inicial porque tiene un sentido menos restrictivo -o así nos lo parece-, aplicable tanto a las formas pronominales que construye el hablante (dominio de la sintaxis) como a aquellas que le vienen dadas, que están lingüísticamente consolidadas. 
español: “¿uno o varios $s e$ ?”). Tenemos, pues, un muestrario de estructuras diferentes con un denominador común, al tiempo que un esbozo de clasificación. Con ello, queda trazado el marco inicial de la 'pronominalidad' en español, punto de arranque y objetivo de nuestro análisis descriptivo, que justamente se ocupará de precisarlo (dicho marco lo es también del análisis contrastivo con las otras lenguas del proyecto).

Las oraciones de (1) no son solo muestras de distintos tipos de estructura, sino que ejemplifican, a nuestro modo de ver, la totalidad de los tipos posibles. Con otras palabras, estamos ante una clasificación de las estructuras pronominales. Se trata de una clasificación con arreglo a concepciones teóricas propias, sustentada en una especie de consenso entre muchas de las que se han propuesto y con una clara orientación didáctica, de la que damos cuenta en trabajos anteriores: p.e., Heredia (2004)3. Es, pues, la clasificación inicial que manejamos y que ilustramos en el siguiente cuadro (donde, además de recoger los ejemplos de (1) y añadir algunos más -sobre todo en la parte derecha-, hacemos las oportunas subdivisiones con sus correspondientes nomenclaturas).

\begin{tabular}{|c|c|c|c|}
\hline & & \multicolumn{2}{|c|}{ DE INCIDENCIA LÉXICA } \\
\hline reflexivas & $\begin{array}{l}\text { (1) Juan se afeita a } \\
\text { diario }\end{array}$ & \multirow{5}{*}{$\begin{array}{l}\text { (8) Juan no se entera de nada } \\
\text { (9) Se ha arrepentido de lo que } \\
\text { hizo } \\
\text { (10) Y ahora ¿qué se le antoja } \\
\text { al niño? } \\
\text { (11) Juan no se acordó de nada } \\
\text { (12) ¿De qué se trata? } \\
\text { (13) El inspector se presentó sin } \\
\text { avisar } \\
\text { (14) Juan se fue a Madrid } \\
\text { (15) Nos hemos visto cinco } \\
\text { películas en el fin de semana } \\
\text { (16) Los papeles se han volado } \\
\text { (17) Ten cuidado, no te caigas } \\
\text { (18) El niño ya a se ha dormido } \\
\text { (19) Por favor, cállese } \\
\text { (20) Cómete la tortilla }\end{array}$} & \multirow{2}{*}{$\begin{array}{l}\text { (IL-1) } \\
\text { de verbo } \\
\text { pronominal }\end{array}$} \\
\hline reciprocas & $\begin{array}{l}\text { (2) Juan y Pedro se } \\
\text { odian }\end{array}$ & & \\
\hline pasivas & $\begin{array}{l}\text { (3) Se necesitan } \\
\text { soluciones }\end{array}$ & & $\begin{array}{l}\text { (IL-2) } \\
\text { de verbo cuasi- }\end{array}$ \\
\hline impersonales & $\begin{array}{l}\text { (4) Se necesita a los } \\
\text { chicos }\end{array}$ & & pronominal \\
\hline $\begin{array}{l}\text { personales } \\
\text { medias }\end{array}$ & $\begin{array}{l}\text { (6) El autobús se } \\
\text { paró } \\
\text { [(7) Estas pastillas } \\
\text { se toman fácil- } \\
\text { mente] }\end{array}$ & & "otras" \\
\hline
\end{tabular}

3 En este trabajo se ofrecen las explicaciones y justificaciones oportunas de la clasificación adoptada, si bien se advierten ciertas discrepancias - casi todas meramente terminológicas-con respecto al que aquí presentamos, que recoge nuestro punto de vista actual. 
1.1. Dejando aquí de lado, pues, las precisiones que la clasificación requiere, lo que ahora interesa subrayar es que, como puede observarse a simple vista, hay en el cuadro una distinción fundamental: la de las estructuras que llamamos de incidencia léxica, que aparecen a la derecha, frente al resto (reflexivas, recíprocas, pasivas, impersonales y medias), que figuran a la izquierda. Identificamos así, en primera instancia, las estructuras pronominales a las que se consagra nuestro diccionario multilingüe.

Una estructura pronominal de incidencia léxica se opone a cualquiera de las otras en virtud de que el tipo genérico de oposición entre la forma pronominal y la no pronominal es distinto: "léxico" -valga la redundanciaen un caso, y sintáctico en otro. La pronominalidad sintáctica supone una peculiar relación del verbo con sus argumentos (o aun una alteración de la propia estructura argumental) con respecto a la forma no pronominal; la pronominalidad léxica, en cambio, incide directamente en el lexema verbal, haciéndolo viable, como sucede en el caso de los "verbos pronominales" (puros): *jactar solo se da dentro de jactarse; o bien alterando su significado (en mayor o menor medida), lo que puede comportar por lo general una alteración de la relación del verbo - de la estructura pronominal- con los demás componentes oracionales. Hay, además, entre ambos tipos genéricos una diferencia añadida (derivada de su distinta naturaleza): las estructuras pronominales de tipo sintáctico son describibles en términos puramente gramaticales, mediante el establecimiento de regularidades, de pautas de alcance general, mientras que, para dar cuenta de las estructuras de incidencia léxica, además de las consideraciones gramaticales pertinentes, se hace necesario, en última instancia, un tratamiento individualizado, caso por caso, un tratamiento léxico, de diccionario, que, o bien consigne la lexicalización plena de la forma pronominal (cuando se trata de "verbos pronominales"), o bien determine el "nuevo significado" (o la simple incidencia en el significado) que comporta la forma pronominal frente a la que no lo es.

$Y$ es que, dentro de estas estructuras que afectan directamente al lexema verbal, distinguimos, como se ve en el cuadro, tres subgrupos (que cumplen todos el requisito genérico del tipo): 1) el de las estructuras pronominales (EE PP) de incidencia léxica (IL) “de verbo pronominal", 2) el de las EE PP de IL "de verbo cuasi-pronominal" y 3 ) el del resto de las EE PP de IL, que en el cuadro designamos como "otras". Veamos los ejemplos (2)-(4):

(2) En español no existe el verbo resignar, existe resignarse.

(3) a. Son cosas bien distintas tirar a alguien y tirarse a alguien...

b. Tampoco es lo mismo correr que correrse.

(4) Yo no dejé los libros en tu casa para que te los leyeras; simplemente, me los dejé. 
Estos tres ejemplos, de índole, por cierto, metalingüística -sobre todo (2) y (3)-, representan los tres subtipos que distinguimos de estructura pronominal de incidencia léxica. En (2) aparece la estructura consistente en un verbo de los llamados pronominales (puros), de los que carecen de contrapartida en forma no pronominal, como es el caso de resignarse y tantos otros (abstenerse, arrepentirse, atragantarse, atreverse, desgañitarse, enterarse, jactarse, obstinarse...). Este tipo de verbos no plantea especiales problemas -salvo los relativos a la amplitud del inventario que las gramáticas suelen hacer de ellos-, toda vez que las estructuras pronominales que forman (IL-1 del cuadro) constituyen un todo inanalizable, son por tanto esos mismos verbos (o dicho de otro modo, verbo y estructura coinciden).

Con (3) ilustramos el concepto de estructura (pronominal de incidencia léxica) de verbo cuasi-pronominal (dichas esructuras conforman el grupo IL-2), y lo hacemos muy gráficamente, con los verbos coloquiales y "malsonantes" tirarse (3 a) y correrse (3 b). Estas estructuras, a diferencia de las anteriores, poseen contrapartida no pronominal: el verbo que las integra, que llamamos cuasi-pronominal, puede aparecer en forma simple, como comprobamos con ejemplos tan elementales como los de (5):

(5) a. Juan tiró a María.

b. Juan corrió la prueba de maratón.

Ahora bien, al construirse pronominalmente -al formar una estructura pronominal- el verbo puede experimentar un cambio sensible de significado (ahorrémonos los ejemplos que podríamos aducir con tirarse y correrse), que suele ir acompañado de un cambio de régimen; esto último sucede en (6 b) con respecto a (6 a):

(6) a. Juan no acordó nada con Pedro.

b. Juan no se acordó de nada.

Cambio de significado y/o de régimen con respecto a la forma verbal simple son, pues, los rasgos con que se definen los verbos cuasi-pronominales y las estructuras constituidas por ellos.

En fin, lo que tenemos en (4), en los fragmentos en cursiva, son ejemplos de otro subtipo de estructura de incidencia léxica (las del grupo IL-3): la estructura pronominal provoca, con respecto a la simple, no un cambio semántico "completo", sino un cambio "de matiz". Es lo que sucede en leerse (te los leyeras) frente a leer; o en dejarse (me los dejé), que mantiene el sema básico de dejar, pero añadiéndole el rasgo 'descuido u olvido'. ¿En qué consiste ese cambio de matiz? La respuesta no es fácil y, desde luego, no parece, en principio, unívoca, puesto que realmente son diversos 
los matices que, según los verbos (e incluso tratándose del mismo verbo), puede introducir la estructura pronominal con respecto a la simple. Pero no podemos entrar ahora en la cuestión ${ }^{4}$. Bástenos consignar la naturaleza matizadora del lexema verbal de este tipo de estructura, y con ello, sustituir la expresión tan vaga otras con que identificamos el grupo por una más precisa, en consonancia con dicha naturaleza ${ }^{5}$. Así:

\section{IL-3}

\section{MATIZADORAS DEL LEXEMA VERBAL (MLV)}

(14) Juan se fue a Madrid.

(15) Nos hemos visto cinco películas en el fin de semana.

(16) Los papeles se han volado.

(17) Ten cuidado, no te caigas.

(18) El niño ya a se ha dormido.

(19) Por favor, cállese.

(20) Cómete la tortilla.

1.2. En cuanto a las otras estructuras pronominales, las de la izquierda del cuadro, que podemos denominar "regulares", ya hemos dicho que entran todas en el dominio de la gramática. Y son las construcciones reflexivas, recíprocas, pasivas e impersonales de la gramática tradicional, a las que hay que añadir las medias, grupo no tan consolidado y definido en los estudios gramaticales de nuestra lengua.

1.2.1. Las estructuras pronominales reflexivas, recíprocas, pasivas e impersonales no ofrecen especiales problemas de identificación, si bien su análisis requiere una serie de precisiones que aquí no procede hacer. Podemos subagrupar el conjunto en dos: reflexivas y recíprocas -por un lado-y pasivas e impersonales -por otro.

De las estructuras reflexivas y recíprocas solo vamos a decir que se identifican en virtud de sus posibilidades de expansión con los sintagmas, respectivamente, de la reflexividad (a sí mismo) y de la reciprocidad (el uno al otro $)^{6}$. Y en cuanto a las pasivas e impersonales (las pasivas e impersonales

4 En Heredia (2009: 114-125) formulamos una hipótesis al respecto.

5 La denominación completa sería estructuras pronominales (de incidencia léxica) matizadoras del lexema verbal (MLV).

6 Pensamos en las reflexivas y recíprocas de complemento directo. Por lo que respecta a las reflexivas, hay que precisar que el sintagma en cuestión no es solo el de $3^{\mathrm{a}}$ persona sino 
reflejas de la tradición gramatical), lo más reseñable es el hecho de que su sujeto lógico (latente, nunca presente) refiera a un ente humano de carácter indeterminado; por lo demás, ambas se hallan -por así decir-en "distribución complementaria", puesto que su semantismo esencial es el mismo; sin embargo, son construcciones sintácticamente distintas, limitándose las primeras a verbos transitivos.

1.2.2. Mayor atención nos merecen las estructuras pronominales medias, por lo que vamos a dedicarles un examen más detenido. De cierta forma, constituyen un grupo fronterizo que, aun perteneciendo a las estructuras pronominales regulares, se acercan a las de incidencia léxica. El siguiente repertorio oracional contiene muestras de lo que llamamos estructura pronominal media:

(7) a. Sus opiniones se basan en datos reales.

b. La salud se debilita con la mala alimentación.

c. Carlos se arruinó en dos años.

d. La rana se convirtió en un hermoso príncipe.

e. Muy poca gente se acostumbra a la soledad.

f. Los niños se divierten solos.

g. La gripe se cura con aspirinas.

h. El que juega con fuego se quema.

i. La tormenta se ha alejado.

Aunque no puede decirse que este tipo de estructuras y su propia denominación estén firmemente asentados en la tradición gramatical, creemos que hay suficientes razones para, cuando menos, establecer el grupo como tal, reconociendo la existencia de una estructura pronominal distinta

que caben asimismo los de $1^{\mathrm{a}}$ y $2^{\mathrm{a}}$ (singular y plural): a mí mismo, a ti mismo, etc. Reflexivas pronominales son también las de complemento indirecto (Juan se dijo que...) o las de dativo pronominal (No me gusto nada). La reflexividad, no obstante, no va ligada necesariamente a la expresión pronominal (Juan trabaja para sí mismo) y, por otro lado, hay estructuras que son pronominales y reflexivas (pero no pronominales reflexivas): Juan se asusta de sí mismo. Mayores precisiones requieren las recíprocas (v. al respecto el revelador trabajo de I. Bosque 1985). Señalemos únicamente que el sintagma de la reciprocidad es, para ser exactos, el uno P el otro (donde $\mathrm{P}=$ preposición), que hay también pronominales recíprocas de complemento indirecto (Nos dijimos cosas terribles el uno al otro) y dativo pronominal (Pedro y María se gustan mucho el uno al otro) y que se dan los otros casos señalados en las reflexivas: la reciprocidad no va ligada a la expresión pronominal (Juan y Pedro trabajan el uno con el otro) y hay estructuras que son pronominales - por un lado- y recíprocas - por otro- (pero no pronominales recíprocas): Pedro y María se van a casar el uno con el otro. 
de las demás (reflexivas, pasivas...) que podemos denominar media. Ello, aun admitiendo que la constitución del grupo -su delimitación respecto a los otros y su configuración interna- y la adecuación del nombre que lo identifica no dejan de suscitar problemas y opiniones encontradas entre los estudiosos ${ }^{7}$.

El criterio definidor de las estructuras medias es que se produce en ellas un proceso de intransitivación verbal, la conversión de un verbo originariamente transitivo en intransitivo. También se ha indicado (v. cuadro clasificatorio en 1) que, dentro de las estructuras medias, las hay "de persona" y "de cosa" (esto es, que remiten a sujetos personales -0 , más exactamente, animados- $y$ a sujetos inanimados). En las oraciones de (7) podemos comprobar cómo unas - (7 a, b, g, i)- contienen sujetos inanimados y otras - (7 c, d, e, f, h)sujetos animados. La condición intransitiva del verbo no es, en cambio, inmediatamente perceptible, pero sí que lo es el carácter transitivo de ese verbo en su forma no pronominal, lo que se pone de manifiesto al aducir un repertorio oracional como el de (8):

(8) a. Juan basa sus opiniones en datos reales.

b. La mala alimentación debilita la salud.

c. Las malas inversiones y los gastos descontrolados han arruinado a Carlos.

d. El beso de la doncella convirtió en príncipe a la rana.

e. Hay que acostumbrar a la gente a respetar el medio ambiente.

f. No hace falta que nadie divierta a los niños... [: se divierten solos].

g. Las aspirinas curan la gripe.

h. Estaban jugando con fuego y Paloma quemó a Nacho.

i. El viento ha alejado la tormenta.

Esta es la llamada alternancia transitiva, el requisito primario que nos permite considerar una estructura pronominal como media: el verbo en forma pronominal que la integra y que se define como intransitivo ha de encontrar correspondencia con un uso transitivo de ese mismo verbo en su forma no pronominal. Así, por ejemplo, en (7 a), para poder analizar se basan como media $-\mathrm{y}$ postular un proceso de intransitivación que hace de basarse un

7 En Heredia (2004), donde tratamos precisamente Sobre el concepto de estructura pronominal media, debatimos ampliamente esas y otras cuestiones y damos cuenta explícita de nuestra postura y nuestros propios criterios analíticos, que son los que aquí adoptamos sin poder entrar en su justificación. Para ello, pues, remitimos al lector a dicho trabajo. 
verbo intransitivo-se ha de comprobar la existencia de construcciones como (8 a), donde aparece el verbo en forma no pronominal -basar-con su valor transitivo originario.

No podemos entrar aquí en mayores explicaciones sobre la intransitivación subyacente a este tipo de estructuras, pero sí hemos de precisar algo acerca de ese criterio inicial de reconocimiento (del proceso y de la propia estructura) que es la alternancia transitiva. Volvamos a los ejemplos de (7), concretamente al primero, (7 a), que encuentra su correspondencia transitiva en (8 a). Según ello, en tanto en cuanto existe basar como verbo transitivo, podemos analizar basarse -a partir de la forma verbal se basan que aparece en (7a) - como verbo intransitivado al tiempo que estructura pronominal media. Sin embargo, hay que advertir que eso solo es válido en la medida en que existe de hecho la correspondencia en cuestión, en que se da la alternancia transitiva concreta, como sucede en la comparación examinada. Pero, ¿qué ocurre, por ejemplo, en (7 a')?, ¿podemos hablar de estructura media?

(7) a’ ¿En qué te basas?

Aquí, basarse es intransitivo, pero no podemos decir que haya habido intransitivación -ni que estemos ante una estructura media-, puesto que no existe contrapartida transitiva estricta:

(8) a’ ¿En qué te basa Juan?

Mientras que en ( 8 a), el complemento directo sus opiniones coincide con el sujeto de (7 a), no se puede formar una oración (*8 a') cuyo complemento directo te sea sujeto $(t u ́)$ de ( 7 a'). Concluimos entonces que (7 a) es una estructura media y que (7 a') no lo es; dicho de otro modo, que con el verbo basar pueden darse únicamente estructuras pronominales medias con sujeto no personal (aquellas estructuras pronominales que, como (7 a'), llevan sujeto personal se analizan de otra manera ${ }^{8}$ ).

Queda así perfilado nuestro concepto de medialidad, el criterio de identificación de una estructura pronominal de tipo medio:

8 Basarse alguien en alguien o en algo, al carecer de contrapartida transitiva (*Basar a alguien en alguien o en algo), es una estructura pronominal de incidencia léxica (de verbo cuasi-pronominal). Nótese cómo basarse alguien incorpora en su significado algo así como 'las ideas, palabras, opiniones, argumentos, relatos... propios', cosa que no sucede con basar (o basarse algo), lo que apunta a ese cambio semántico característico de muchos verbos cuasi-pronominales. 
Una estructura pronominal media es una estructura intransitiva integrada por un clítico reflejo y un verbo originariamente transitivo, de modo que la oración intransitiva resultante remita a otra transitiva con el mismo verbo cuyo (tipo de) complemento directo pueda coincidir con el (tipo de) sujeto de la primera9.

Como puede verse en (7) y queda reflejado en el cuadro clasificatorio inicial, dentro de estas estructuras trazamos una distinción entre las que "contienen" sujeto animado e inanimado o, más simplemente -como las denominamos-, entre las estructuras medias de persona y de cosa. Se trata de una subdivisión que obedece más a razones semánticas y de uso que a criterios estrictamente gramaticales, por lo que no cabe hablar de diferenciación categorial. Esto significa que, si bien partimos de la existencia de una única categoría (diferenciada del resto de las estructuras pronominales), por la que asignamos el mismo estatus de medias a estructuras como las de La tormenta se acerca y Juan se acerca, la inviabilidad de, p.e., \#La mesa se alegra -frente a la normalidad de Juan se alegra- aconseja la subclasificación categorial y el establecimiento de dos subtipos: el de las medias de cosa y el de las de persona.

Las estructuras pronominales medias de cosa tienen como particularidad (frente a las de persona) el hecho de que, al tratarse de oraciones con sujeto no personal, la única forma de clítico reflejo que puede aparecer es se. Esto las asemeja a las pasivas reflejas (o a las impersonales que se neutralizan con éstas $)^{10}$. Así, por ejemplo:

(9) El reloj se estropeó [media].

(10)a. Se han obtenido los mejores resultados [pasiva].

b. Se ha declarado la guerra [pasiva o impersonal].

9 Pero hay algunos verbos no propiamente transitivos (o de transitividad discutible) que dan lugar a estructuras medias. Nos referimos a verbos del tipo interesar, preocupar. En efecto, los objetos de oraciones como A Juan le interesa María/la política o A Juan le preocupa Maríal la política no serían claramente objetos directos, pues, como vemos, son referidos por le y no por $l o \mathrm{y}$, sobre todo, no pueden ser sujetos de las pasivas correspondientes, que son claramente agramaticales: *Juan es interesado por María/la política, *Juan es preocupado por María/la política. En parecidas circunstancias se encuentran verbos como enfadar, disgustar, divertir, alegrar, molestar... Pese a todo, y aunque la cuestión merece un tratamiento más detenido, nos inclinamos por analizar interesarse, preocuparse, enfadarse, disgustarse, divertirse, alegrarse, molestarse... como estructuras pronominales de tipo medio.

10 Cuando el sintagma nominal, como la guerra en (10 b), es singular e inanimado, puede decirse que se da una especie de neutralización entre la formulación pasiva e impersonal. 
Externamente tenemos los mismos elementos funcionales en (9) y (10). Dejando al margen la cuestión -no irrelevante- del orden (que, como se ve, es distinto en uno y otro caso), podríamos decir que la semejanza es total. Sin embargo, pese a ello, pese a la posible confusión que puede darse entre ambos tipos de estructura, las consideramos distintas y postulamos una oposición entre ellas, que se pone de manifiesto en la imposibilidad de parafrasear (9) mediante un giro pasivo: El reloj se estropeó no equivale a El reloj fue estropeado, a diferencia de (10), donde a) Se han obtenido los mejores resultados $=$ Han sido obtenidos los mejores resultados y b) Se ha declarado la guerra $=$ La guerra ha sido declarada. Con otras palabras, cuando decimos que el reloj se estropeó no decimos (necesariamente) que alguien lo estropeara (sí decimos - $\mathrm{O}$ damos a entender- en cambio, que alguien ha obtenido los mejores resultados o que alguien ha declarado la guerra al proferir los enunciados de (10) ). Y es que la transitividad permanece de alguna manera en una pasiva (refleja o no), y desaparece ("se hace" intransitividad) en una media, donde, al incrementarse el verbo con el clítico e intransitivarse, la "acción" verbal se convierte en simple 'suceso'.

La oposición entre estructuras pronominales medias y pasivas se da, como acabamos de ver, precisamente a través de las medias de cosa, lo que supone la principal razón para el establecimiento del propio subgrupo. Ahora bien, hay que advertir que esa oposición entre pasivas y medias no siempre se presenta nítida. Así, una oración como

(11) ¿Se ha abierto la puerta?

resulta ambigua en su interpretación media o pasiva, puesto que puede entenderse que se hace una pregunta, bien sobre si se ha producido un hecho, o bien sobre si alguien ha producido ese hecho. Y es que las diferencias entre unas y otras estructuras son más "profundas" que aparentes (en las medias -insistamos- se da un proceso intransitivador por el que hay una reducción a un argumento de los dos del verbo transitivo originario; en las pasivas, pese a que solo aparece un argumento léxico -el sujeto gramatical pero objeto lógico-, a él hay que añadir un argumento implícito, el del sujeto lógico). Existen, ciertamente, algunas marcas externas que propenden a reflejar la diferencia u oposición estructural; así, el orden de palabras (con tendencia al sujeto pospuesto en la pasiva), la indeterminación del sujeto (que no puede darse en las medias), el tiempo verbal, el tipo de verbo... Pero no son factores absolutamente decisivos. Por ello, a menudo es el contexto el que nos da la clave:

(12) a. La gripe se cura con aspirinas.

b. En mi familia la gripe se cura con aspirinas.

c. En mi familia se cura la gripe con remedios caseros. 
En (12 a) lo que se viene a decir es que 'la gripe se cura por sí misma con la ayuda de aspirinas' ${ }^{11}$, y en este sentido estamos ante una estructura media. La estructura pronominal de (12 b) también lo sería, pues esta oración solo se diferencia de la anterior en el elemento inicial que introduce: $E n \mathrm{mi}$ familia. Pero esa expresión opera como contexto verbal inmediato que traza un ámbito personal donde cabe un "agente humano indeterminado" que ejerza la acción de curar; estamos, pues, ante una pasiva refleja. Y aún más en (12 c), en que, además de mostrar un orden (verbo-sujeto) más acorde con las pasivas, el contexto se ve reforzado en su interpretación personal mediante con remedios caseros.

Un último apunte a propósito de la oposición que acabamos de ver. En el cuadro de (1) incluíamos entre paréntesis como ilustración de las estructuras medias de cosa el ejemplo siguiente:

(13) Estas pastillas se toman fácilmente.

Una estructura como la que se presenta en (13) posee una condición especial: sin ser ambigua, parece hallarse en el límite entre la construcción media y la pasiva. La oración (13) y otras similares, pese a contener verbos que denotan actividades humanas e inducir por tanto a una interpretación pasiva, presentan unas características que las vinculan con las estructuras medias. En efecto, lo que denotan no son tanto acciones, situaciones o acontecimientos, sino propiedades inherentes del sujeto. Llamamos a este tipo de estructuras medio-pasivas. Se trata, como hemos indicado, de un grupo intermedio que, por razones formales (tipo de verbo), remiten a las estructuras pasivas pero que, en lo que respecta al contenido, se aproximan a las medias, y por eso, aun reconociéndoles su propia individualidad, nos inclinamos a considerarlas dentro de estas.

Las estructuras pronominales medias de persona incluyen, lógicamente, las que tienen sujetos de primera y segunda persona gramaticales, con lo que el clítico reflejo, además de se (singular y plural), puede ser me, te, nos u $o s$. Las estructuras pronominales medias de persona limitan y se relacionan directamente con las reflexivas (de objeto directo); su semejanza formal hace que tiendan incluso a confundirse. Sin embargo, se trata de estructuras distintas, entre las cuales se establece una relación opositiva que se cifra

11 Conviene resaltar el papel instrumental de expresiones como con aspirinas en muchas oraciones que contienen estructuras medias. En la alternancia transitiva, el instrumental puede "pasar" a sujeto gramatical: Las aspirinas curan la gripe. En casos de este tipo se da, además, una equivalencia semántica entre la oración transitiva y la "oración" media. 
gramaticalmente en términos de intransitividad / transitividad y adopta como criterio de identificación el distinto comportamiento de unas y otras con respecto al sintagma a sí mismo (y variantes morfológicas): mientras que una estructura reflexiva puede expandirse con dicho sintagma, esto no es posible en el caso de una media. Así, frente a la reflexiva de (14 a), que admite el incremento a nosotros mismos -como vemos en (14 b):

(14) a. Isabel y yo nos consideramos capaces para la tarea.

b. Isabel y yo nos consideramos a nosotros mismos capaces para la tarea,

es inviable (15 b) como expansión de la estructura media (15a):

(15) a. El niño se ha levantado tarde.

b. *El niño se ha levantado a sí mismo tarde.

En (15 a), analizamos se ha levantado como una forma verbal intransitiva "derivada" de un verbo transitivo levantar; por el contrario, en (14), con el incremento a nosotros mismos (explícito o implícito), la función de complemento directo -cuyo referente es sin embargo el mismo que el del sujeto: 'Isabel y yo'- es clara y el verbo es, por tanto, transitivo.

Hay que señalar, no obstante, que el recurso al sintagma a sí mismo como prueba de reconocimiento de la transitividad-reflexividad (y de la intransitividad-medialidad) está lejos de ser definitivo. A la vista de la escasa viabilidad de, p.e., ?Juan se lava a sí mismo, habríamos de concluir que lo que se suele considerar prototipo de construcción reflexiva, lavarse, no lo es en realidad, dado que no acepta fácilmente el incremento a sí mismo; menos aceptable nos resulta aún ??Juan se disfraza a sí mismo con otro verbo, como disfrazarse, que parece también reflexivo (con el desdoblamiento que caracteriza a estas construcciones). Sucede que aquí la prueba falla: al lado de casos muy claros (como *Juan se levanta a sí mismo, que sería por tanto una estructura no reflexiva, esto es, media), hay otros -como los citados de lavarse o disfrazarse- en que el incremento con el refuerzo tónico produce secuencias de dudosa gramaticalidad, sin que por ello hayamos de concluir que no son reflexivas las estructuras en cuestión. Aunque a veces - para llegar a esa misma conclusión- lo que se hace es aceptar como plenamente normales secuencias como Juan se lava a sí mismo o se disfraza a sí mismo, no nos parece que esta sea la solución adecuada, puesto que fuerza la realidad de los hechos a la propia explicación de los mismos.

Repitámoslo: el criterio no es concluyente; solo funciona positivamente: la aceptación natural del refuerzo tónico asegura la condición reflexiva de la estructura pronominal, pero la falta de esa aceptación no la excluye 
por completo. Por otra parte, hay que consignar casos que en su totalidad llamaríamos "dudosos" (pese a que plantean diversos tipos de duda): bañarse o ducharse se interpretan normalmente como estructuras medias (Me bañé [*a mí mismo] en el mar, o Sólo me ducho [*a mí mismo] cuando tengo calor), pero serían reflexivas en contextos especiales: Me bañé (= embadurné) a mi mismo de pintura o Con la manguera duché a María, duché a los niños y acabé duchándome a mí mismo. Otro verbo típicamente medio como asustarse se hace reflexivo en Juan se asustó a sí mismo al verse en el espejo, incorporando el desdoblamiento propio de la reflexividad -en este caso 'causa/paciente'. La intención del hablante -la expresividad- también puede originar estructuras que se salen de las pautas esperables: no hace mucho oíamos a un político decir "España se ha transformado a sí misma", como dando a entender la firme voluntad de España (de los españoles) en transformarse; y una famosa escritora, recomendando enfáticamente la visión de una película, en una creación ultrarreflexiva -más allá de los límites gramaticales-, decía: "Lleven a sus hijos a verla, pero sobre todo llévense a sí mismos". Hay casos, en fin, simplemente ambiguos, como por ejemplo, secarse, en los que el contexto es determinante: con una toalla y al sol provocan, respectivamente, la interpretación reflexiva o media de la estructura. Estas situaciones, en realidad, apuntan a un desdibujamiento de la oposición entre medialidad y reflexividad, cuyo alcance no estamos en condiciones de precisar, pero que en modo alguno sería total, puesto que estamos convencidos de que, pese a la identidad formal, se trata de estructuras distintas, que transmiten contenidos distintos.

Para concluir con este examen de las estructuras medias de persona, hay que subrayar que el grupo presenta una gran complejidad interna, dada la diversidad de relaciones semánticas en que se traduce la intransitivación verbal, las distintas "acciones" en que puede intervenir un sujeto humano o animado, su grado de "participación" en ellas. Puede decirse que, en general, estas estructuras -y también las de cosa- están formadas, por un verbo, transitivo en origen, de "cambio" o, cuando menos, de objeto afectado. Pero no podemos analizar aquí esta circunstancia y sus implicaciones gramaticales. Por eso no nos va a ser posible detallar el tipo de oposición que las distintas clases de medias personales mantienen con las reflexivas. Pero si trazamos una división genérica entre medias "espontáneas"12 (Juan

12 M. Moliner (1966: s.v. espontáneo) establece, por primera vez en una obra de carácter lexicográfico, lo que llama forma "espontánea", que se aplica "a la forma pronominal de los verbos cuando su significado no es propiamente ni reflexivo ni pasivo, o sea, cuando, tratándose de verbos de naturaleza transitiva, toman mediante el pronombre significado intransitivo", 
se aburrió) -la gran mayoría- y "agentivas" (Juan se levantó), sí que podríamos decir que las primeras se oponen a las reflexivas en términos de (in)agentividad-(in)voluntariedad, oposición que, obviamente, no puede hacerse extensiva a las segundas; en este caso se ha de buscar otro criterio, puesto que la agentividad puede ser común a medias (Juan se levanta) y a reflexivas (Juan se afeita). La clave radica en lo que hemos venido diciendo de unas y otras sobre su naturaleza gramatical -intransitiva en medias y transitiva en reflexivas: estas últimas presentan identidad referencial entre sujeto y objeto, pero no "desaparece" ninguno de ellos, sino que se da una especie de "desdoblamiento"; con una media "agentiva", al carecer de objeto, lo que se da es, más bien, una "acción" del propio sujeto que, simultáneamente, le afecta a él. Esta característica es naturalmente válida para las medias "espontáneas", que tampoco presentan "desdoblamiento" sujeto-objeto, solo que el papel del sujeto es el de mero ente afectado. En esquema:

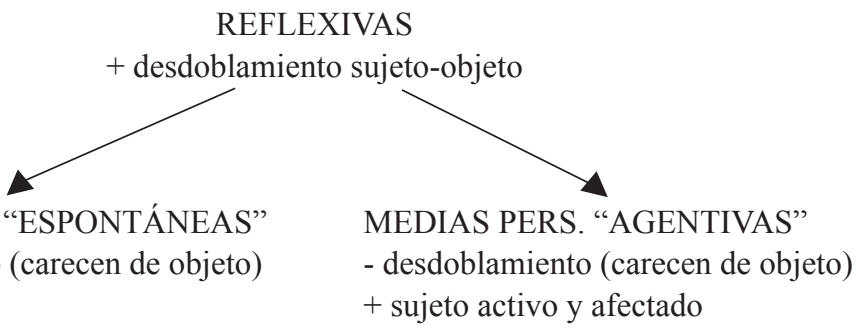

Pero insistamos: los tipos de verbos que entran en estas construcciones, la subclasificación de éstas, en fin, la gramática de la estructura pronominal media de persona (y de la media en general) merece un extenso capítulo aparte.

y pone como ejemplos el puente se hundió y se mató en unas carreras de automóviles. No parece referirse a todas las estructuras que aquí llamamos medias, sino solo a aquellas en que la acción no depende de un agente humano voluntario. 


\section{LAS CONSTRUCCIONES PRONOMINALES EN LA NUEVA GRAMÁTICA DE LA LENGUA ESPAÑOLA DE LA RAE (2009) Y NUESTRO MODELO DESCRIPTIVO}

2.1. Nos hemos detenido en el examen de las EE PP medias porque son la clave, por un lado, para entender el modelo descriptivo propuesto en la Nueva gramática $\mathrm{y}$, por otro, nuestras discrepancias con ese modelo. Y es que la Academia consagra a ellas, aproximadamente, la tercera parte del total que dedica a las construcciones pronominales (frente a un $40 \%$ del tratamiento de pasivas e impersonales y un $20 \%$ de reflexivas y recíprocas).

En realidad, la Nueva gramática no parte del concepto de estructura o construcción pronominal, es decir, no "unifica" la materia, por ejemplo, presentándola dentro de un mismo capítulo, ni aboga por ese denominador común que sería la etiqueta estructura o construcción. Solo la segunda la usa para referirse a las "construcciones medias", al margen de empleos esporádicos del término para otros casos, en sentido no técnico (o no restrictivo). Así, pues, si queremos hacer una consulta al respecto, partiendo de una visión global, no podemos hacerlo. No existe en el índice una entrada (ni aun remitiendo a otras) del tipo construcción o estructura pronominal o refleja, y tenemos que buscar "por partes", fundamentalmente dos: pronombres reflexivos (y reciprocos) y verbos pronominales. Los pronombres reflexivos y recíprocos constituyen sendos apartados del capítulo 16: "El pronombre personal. La correferencia. Las formas de tratamiento". Los verbos pronominales aparecen dentro del apartado 13 -"Las construcciones medias (I). Los verbos pronominales"-, dentro a su vez del capítulo 41: "Oraciones activas, pasivas, impersonales y medias". Esta división parece obedecer - pues no se explicita- a un criterio científico-descriptivo: quedan separadas las construcciones en las que el pronombre átono posee carácter argumental (reflexivos y recíprocos) de aquellas en las que esto no es así; y dentro de estas últimas, aparecen por un lado las pasivas e impersonales (con sendos apartados), y por otro, las construcciones medias (en cuyo apartado se tratan los verbos pronominales).

No vamos a entrar aquí en la consideración académica de las estructuras que llamamos reflexivas, recíprocas (capítulo 16, apartados 4 y 5 respectivamente), impersonales y pasivas (con los apartados 10 del capítulo 41 para las impersonales, 11 para las pasivas y 12 para estas últimas y una comparación entre ambas). Digamos, simplemente, que el tratamiento responde, o aun supera, las expectativas de una obra de la naturaleza de la Nueva gramática. Vamos a centrarnos, pues, en las construcciones medias $\mathrm{y}$ en los verbos pronominales. 
2.2. Como ha quedado apuntado, la primera parte de las construcciones medias se dedica a los verbos pronominales, mientras que la segunda la ocupan aquellas construcciones medias formadas por verbos intransitivos que no son pronominales. $Y$, en relación con todo esto, tenemos un apartado más, el de las construcciones inacusativas (41.4). Al margen de ellas, lo que hace la Academia es reconocer que existen construcciones medias que no están integradas por verbos pronominales, al tiempo que atribuir de hecho a todos los verbos pronominales la condición de verbos medios.

$\mathrm{Y}$ aquí radica uno de los problemas terminológico-conceptuales que presenta el análisis académico de esta materia. ¿Qué es un verbo pronominal? Aunque no se da una respuesta explícita a la pregunta, esta podría ser la que se desprende de dicho análisis: un verbo de tipo medio con la presencia de un clítico reflejo no argumental. Hay, pues, una restricción del sentido de la expresión verbo pronominal: no se aplica a todas las construcciones con presencia de clítico reflejo, sino que hay una identificación con la construcción pronominal media. Ahora bien, verbo pronominal o medio significa algo más de lo que suele entenderse al respecto (concretamente por verbo o construcción media): incluye también las estructuras o construcciones que nosotros consideramos de incidencia léxica (arrepentirse [/*arrepentir], acordarse de [/acordar], dejarse [/dejar]; y es así que, para el tipo de verbos como arrepentirse -pronominales en sentido estricto-, habla de "verbos intrínsecamente reflexivos" o "pronominales inherentes".

Volviendo ahora a las construcciones inacusativas, constituyen estas -como hemos dicho- un apartado propio, si bien no se explicita suficientemente la relación que mantienen con las demás, singularmente con las medias. Parece darse una consideración "transversal" de la categoría: hay medias que son inacusativas y otras que no lo son, mientras que las inacusativas parecen ser todas medias. No queda muy claro. Como tampoco queda la determinación de la propia categoría y -como acabamos de indicarlas consecuencias que ello comporta en el panorama general. Queremos decir que la inclusión de las construcciones inacusativas parece obedecer a la necesidad de "decir algo" a propósito de este tipo de construcciones (o verbos intransitivos) tan tratadas en los estudios lingüísticos actuales, de hacerse eco de un punto de vista tan en boga -y, sin duda, tan sugerente-, pero a la vez tan problemático, dejando en el aire el acoplamiento con el resto de la materia.

Adelantándonos a la crítica que, junto con la comparación con nuestro modelo descriptivo, haremos en el próximo apartado, entendemos que la inacusatividad requiera un tratamiento por parte de la Academia, pero -a nuestro entender- un tratamiento un poco al margen, toda vez que la categoría y su ajuste a la materia que nos ocupa no están exentos de problemas. Por 
mencionar uno, se nos presenta esta-simplificando algo las cosas-como fruto de la división de los verbos intransitivos (que entran en las construcciones u oraciones activas) en dos tipos, según 1) "la construcción, en la lengua antigua, de sus tiempos compuestos con ser" y 2) "su aparición en cláusulas absolutas". Así, llegar, 1) "Es llegado el momento" y 2): "Llegado Juan, ..." Frente a ellos están los otros intransitivos, los inergativos: sonreír, que tanto en la lengua antigua como en la actual forman sus tiempos compuestos con haber y no pueden aparecer en cláusulas absolutas ("Sonreída María..." es agramatical).

Dentro de la nómina de inacusativos se incluyen verbos "que denotan presencia, existencia, aparición, seguimiento, manifestación de algo y nociones contrarias", y se ejemplifican con amanecer, aparecer, brotar, desaparecer, flotar, manifestarse, morir, nacer, ocurrir, pasar, salir, suceder, surgir, venir... Solo una objeción: ¿por qué se cita dentro de estos verbos, sin dejar constancia de ello, un pronominal como manifestarse? La otra que podríamos hacer -p.e., respecto a flotar- la resuelve la Academia diciendo que algunos verbos de este tipo "ofrecen resultados inestables cuando se someten a las pruebas de inacusatividad" (p.e., salir y otros que añade a la lista: existir, faltar, quedar, sobrar... A continuación habla de otro grupo de inacusativos "que expresan cambio de estado, como los pronominales asomarse, arrodillarse, hundirse, enamorarse". Aquí, se está reconociendo -y nos parece bien- la condición "transversal" de la categoría, pues por primera vez se incluyen de forma explícita verbos pronominales dentro de los inacusativos; a ellos "se suman otros verbos de cambio de estado no pronominales: envejecer".

Frente a los inacusativos están los inergativos, que "pueden pertenecer a diversas clases semánticas". Los hay de emisión: apestar, brillar [...] parpadear [...] zumbar. "Otros expresan manera de moverse: arrastrarse, botar, correr, gatear, girar, nadar, rodar, volar". A propósito de estos, llama la atención, además de la inclusión de girar (que, por un lado, puede ser transitivo $\mathrm{y}$, por otro, admite la alternancia girar-girarse) especialmente el pronominal arrastrarse, del que tampoco se hace constar su condición; pues bien, este verbo admite la cláusula absoluta (“Arrastrado Juan...”), si bien en un sentido pasivo ('Juan ha sido arrastrado'); y como él, otros (p. e., acercarse). Esto parece excluir a arrastrarse (en contradicción con la tesis académica) y a acercarse de los inergativos, aunque tampoco pueden incluirse dentro de los inacusativos. La conclusión lógica es que no hay solo dos, sino tres tipos de verbos intransitivos (o intransitivados): un nuevo grupo, además de inacusativos e inergativos, comprendería verbos como arrastrarse o arrodillarse. Como puede verse, quedan muchos cabos sueltos respecto a la noción de inacusatividad y el tratamiento que la Nueva gramática hace de ella. 
2.3. Centrémonos en las construcciones medias y en las discrepancias sobre el particular (y sobre las estructuras pronominales en general) entre el modelo descriptivo de la Academia y el nuestro. Al final del apartado introductorio (41.1. Introducción. Oraciones activas y pasivas), en el subapartado $41.1 \mathrm{j}$ (donde se enumeran y describen brevemente los temas que se van a tratar en el capítulo), se dice a propósito de las construcciones medias:

Se forman con verbos intransitivos que describen procesos en cuyo desarrollo no interviene activamente el sujeto: Las hortensias se marchitaron.

Y ya dentro del apartado correspondiente (41.13) se añade:

[...] el término VOZ MEDIA se aplica tradicionalmente a los verbos intransitivos que designan cambios de estado, así como procesos experimentados por algún sujeto que no suele ejercer control directo sobre ellos.

En fin, en otro lugar de ese mismo apartado, en el que se tratan -recordémoslo- los verbos pronominales dentro de las construcciones medias, se relacionan como "verbos [medios] que denotan cambio de lugar o de posición":

acercarse, acostarse, agacharse, alejarse, desviarse, inclinarse, ladearse, lanzarse, levantarse, moverse, reclinarse, sentarse, separarse, torcerse, tumbarse.

2.3.1. Atendiendo a la primera cita, nos encontramos ya con una explicación confusa cuando no contradictoria. ¿Cómo se puede afirmar sin temor a causar sorpresa que una "construcción media se forma con un verbo intransitivo", cuando marchitar es verbo transitivo? Podría entenderse que construcción se refiera a $-\mathrm{o}$ se ejemplifique con-las hortensias + se marchitaron. Pero en tal caso, lo que extraña es que no se diga nada acerca del proceso de intransitivación que se da en marchitar cuando va incrementado con el clítico. Puede decirse que la Academia omite dicho proceso al tiempo que lo admite, pues en ningún momento de las páginas dedicadas a los verbos pronominales medios hace referencia a él.

Si nos fijamos en los otros dos párrafos citados, llama la atención la indecisión de la Academia a la hora de definir sus propios conceptos, así como cierta falta de coherencia. ¿Puede hablarse de voz en el caso de las construcciones medias? ¿Se refieren a lo mismo construcción y voz? Ciertamente, en el apartado introductorio del capítulo se hace una reflexión al respecto (más en concreto, a los conceptos 'voz' y 'diátesis'), pero el caso 
es que, tras poner en duda incluso para la activa y la pasiva la conveniencia de emplear el término voz, aquí se vuelve a traer, eso sí, matizado con el adverbio tradicionalmente. Y la pregunta es, entonces: ¿acepta la Academia esa consideración tradicional? ${ }^{13}$ Dejando de lado este asunto, hay una inconsistencia de mayor calado: ¿cómo se puede definir una construcción (o una voz) hablando de verbos intransitivos cuyo sujeto no controla los procesos que designan y ejemplificar después con verbos como los que aparecen en la nómina citada? Es cierto que se dice que el sujeto "no suele ejercer control". Pero entonces, aparte de que la definición es insatisfactoria ¿es tan escaso el número de verbos que no cumplen el criterio definidor para que hagamos de ellos una pequeña excepción? ¿No es mejor buscar otro criterio? Creemos que nuestra definición de estructura pronominal media -nuestra delimitación del concepto-, sin estar exenta de problemas, es mucho más clara y precisa que este "definir-no definir-contradecirse" del que da muestras la Academia en este punto.

2.3.2. Pero nuestra postura y el criterio académico no se diferencian solo en la formulación. Discrepamos sobre el alcance de los conceptos 'verbo pronominal' y 'construcción media', o para ser exactos, respecto a la relación que uno y otro guardan entre sí. Dice la Academia de los verbos pronominales:

Se llaman [así] los que contienen en su conjugación formas pronominales átonas con rasgos de persona.

Y cita como pronominales arrepentirse, cansarse y marearse (41.13a), esto es, un verbo pronominal inherente y dos que no lo son. Hace, en fin, una precisión ulterior:

El morfema pronominal átono que caracteriza a los verbos pronominales no es argumental, por lo que no le corresponde una función sintáctica (41.13f).

En cuanto a construcción media, se reconoce la utilidad del término para referirse a "oraciones intransitivas que expresan cambios de estado, sea con verbos pronominales $[\ldots]$ o no pronominales $[\ldots]$ " (41.13e).

13 Solo unos párrafos más tarde se nos dice: “Como es sumamente polémico que en español exista una voz media [...], se evitará aquí ese término" (41.13 e). Pero lo que valía para voz va a valer, como veremos, para construcción media. 
2.3.2.1. En la caracterización académica de los verbos pronominales hay dos notas definidoras: pronombre átono con rasgos de persona y pronombre átono no argumental. $\mathrm{Y}$, de este modo, quedan excluidas $-\mathrm{y}$ separadas en cuanto a tratamiento- las construcciones pasivas e impersonales (que se examinan, sin embargo, dentro del mismo capítulo), reflexivas y recíprocas. El doble criterio nos parece perfectamente legítimo, con la pequeña salvedad ya comentada: la dispersión inicial de una materia que, siquiera desde un punto de vista didáctico, requeriría un tratamiento conjunto (sin perjuicio de ulteriores "separaciones"). Es más, la exclusión comentada se produce de hecho, sin un reconocimiento explícito desde el principio y con solo el apunte tardío que hemos visto, insuficiente a nuestro entender.

2.3.2.2. Pero la principal fuente de equívocos se deriva de la inclusión de los verbos pronominales dentro de las construcciones medias, con lo que se nos viene a decir que, si bien hay construcciones medias no formadas por verbos pronominales, "todo verbo pronominal es medio". Tal identificación nos parece errónea.

Nuestra postura -ya se ha visto-, que rehúye la expresión verbo pronominal salvo para referirse a los "pronominales inherentes", diverge por completo de la de la Nueva gramática. Para nosotros, hay una distinción fundamental entre estructuras medias (que forman parte de las que llamamos "regulares") y estructuras de incidencia léxica, y los "verbos pronominales" de la Academia los repartimos en dos categorías: los que son medios (acercarse, cansarse, enfadarse, entrenarse, informarse, levantarse...) y los que constituyen estructuras pronominales de incidencia léxica (jactarse, acordarse de, caerse, leerse), y ello, independientemente de que algunos de estos puedan designar cambios de estado (arrepentirse). En este caso, para nosotros, son más importantes las diferencias atribuibles a cada una de las categorías que la naturaleza semántica común de algunos de esos verbos. Ciertamente, no hay una identificación explícita por parte de la Academia entre la totalidad de estructuras que llamamos nosotros de incidencia léxica y las construcciones medias, pero el hecho de tratar aquellas dentro de estas -sin las precisiones o comentarios oportunos-ya es de por sí suficientemente significativo.

Por lo demás, muchos de los verbos pronominales no denotan cambios de estado, y esto va en contra de su consideración como medios. Para algunos, la Academia da alguna explicación (p.e., alzarse en La torre se alza...). Pero para otros no: u omite esa explicación (decidirse a, despedirse de...) o evita la mención de buena parte de ellos (abstenerse, aprovecharse de, asegurarse de, comprometerse a, dedicarse a, empeñarse en, lamentarse de, 
llamarse, negarse a, oponerse a, servirse de, etc. $\left.{ }^{14}\right)$. Son lo suficientemente numerosos como para poner en tela de juicio la consideración de todos los verbos pronominales como medios.

Aún más grave, y más contradictorio, es la mención de verbos transitivos dentro de los pronominales $y$, por ende, dentro de las construcciones medias (que son, recordémoslo, intransitivas). Es lógico que sean examinados, pero habría que hacerlo aparte, con algún tipo de salvedad o, cuando menos explicando el porqué de su inclusión en este punto. Nos referimos a casos tan conocidos como comerse una tortilla, fumarse un cigarrillo, leerse el periódico, encontrarse un reloj, dejarse las gafas, etc. Huelga decir que, para nosotros, estos verbos pronominales nada tienen que ver con una estructura pronominal media.

2.3.2.3. Y a propósito de verbos transitivos, hay una cuestión que, aun esbozada por la Academia, no recibe una consideración especial. Se trata de lo que, en nuestra concepción (v., p. e., Heredia 2009: 118-120), hemos llamado tríadas, que podemos presentar mediante el siguiente esquema:

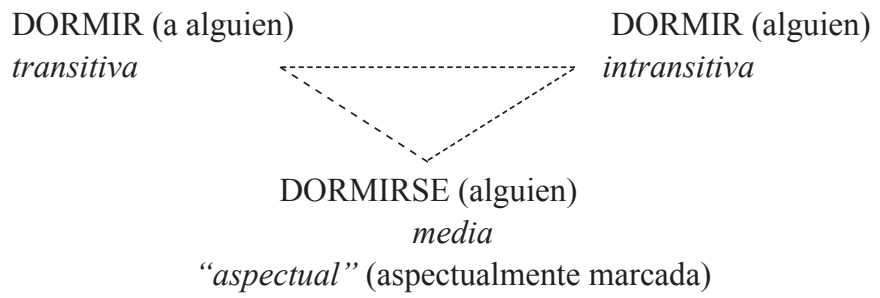

El verbo dormir, en casos como El niño ha dormido bien, es verbo intransitivo. Pero presenta también usos transitivos: He dormido al niño. Se trata, pues, de un verbo de los llamados neutros o, con más exactitud, diatéticamente neutros (Lázaro Mora 1983: 305). Pues bien, junto a estas dos versiones o, si se quiere, dos verbos dormir homónimos, existe asimismo la forma pronominal dormirse, que a su vez puede usarse transitiva o intransitivamente. De este modo, tenemos cuatro posibilidades:

14 Los verbos relacionados llevan la mayor parte de ellos complemento preposicional, incluido abstenerse. En este, sin embargo, no hemos añadido la preposición de porque es un verbo pronominal inherente (no existe *abstener), mientras que los otros son muestras de lo que llamamos verbos cuasi-pronominales; los hemos marcado con la preposición para hacer ver que tienen contrapartida no pronominal y, en este caso, también no preposicional. 
(16) a. He dormido al niño [trans.].

b. El niño ha dormido bien [intrans.].

c. Me he dormido al niño [pron. trans.].

d. El niño se ha dormido [pron. intrans.].

Vamos a prescindir de (16 c), que es una variante enfática de (16 a) -subrayando la hazaña costosa de haber "dormido al niño". Limitándonos, pues, a (16 a, b y d), y habida cuenta de que la relación-oposición entre las dos primeras está bien establecida, el interés de la comparación se centra en (16 d), en su relación-oposición con cada una de las otras dos, esto es, en su propia definición estructural. Según indica el esquema, la estructura pronominal dormirse (alguien) mantiene una doble oposición, por un lado con el intransitivo dormir (alguien), y por otro, con el transitivo dormir (a alguien). La oposición con la formulación intransitiva se concreta en términos que, provisionalmente, pueden considerarse aspectuales ('principio de acción' en dormirse / 'curso de acción' en dormir); la oposición con la transitiva es de otra índole -sintáctica, no léxico-"aspectual"-: medialidad (que es una forma de intransitividad) / transitividad. Esto es, dormirse mantiene con dormir (alguien) una relación semejante a la de caerse con caer; mientras que con dormir (a alguien) mantiene una relación semejante a la que hay entre alegrarse y alegrar (a alguien), estropearse y estropear (algo o a alguien), etc. Dormirse, en fin, se define como estructura pronominal media (con relación a dormir transitivo) y "aspectual”, o mejor, aspectualmente marcada (con relación a dormir intransitivo $)^{15}$. Como hemos dicho, llamamos tríadas a las configuraciones verbales como la que presenta dormir (esto es, formulación transitiva, intransitiva -homónimas- y pronominal) y con una relación interna semejante. Candidatos a constituir tríadas son, entre otros, verbos como:

(17) a. CALLAR: callar (a alguien) / callarse (alguien) / callar (alguien)

b. SUBIR-BAJAR: subir-bajar (a alguien) / subirse-bajarse (alguien) / subir-bajar (alguien)

15 La etiqueta "aspectual" (comillas incluidas) no quiere decir que solo la forma pronominal contenga información aspectual, sino que es la forma marcada en cuanto al aspecto (a diferencia de la forma no pronominal intransitiva, que también "es" aspectual, pero "no marcada"). Por otra parte, si la oposición dormirse / dormir (a alguien) se define como 'media/transitiva', esto significa que no es "aspectual" y que dormir (a alguien) coincide aspectualmente con dormirse. Así es, en efecto. 


\section{c. PASEAR: pasear (a alguien) /pasearse (alguien) /pasear (alguien). \\ d. DESPERTAR: despertar (a alguien) / despertarse (alguien) /despertar (alguien). \\ e. MEJORAR: mejorar (a alguien) /mejorarse (alguien) /mejorar (alguien). \\ f. CAER [dialect.]: caer (a alguien) / caerse (alguien) / caer (alguien).}

No podemos entrar en un análisis detallado de los ejemplos de este repertorio ni, a través de ellos, en el del concepto de tríada y sus implicaciones gramaticales (aquí se ponen en juego las nociones de transitividadintransitividad, pronominalidad, medialidad, aspectualidad...). Subrayemos, no obstante, que una estructura pronominal que entra en una configuración triádica requiere un doble análisis, una doble caracterización: 1) en tanto que presenta alternancia transitiva, se opone a la estructura correspondiente en virtud de su condición de media (esto es, intransitiva o intransitivada) y 2) en la medida en que se diferencia significativamente de la versión intransitiva no pronominal, se opone a ésta por el matiz que incorpora (aspectual o de otro tipo). Así, definimos dormirse como media -con respecto a dormir (a alguien)- y como incoativa -con respecto a dormir (alguien)-; esto es, dormirse -media (y por tanto, intransitiva) e incoativa- se opone a dormir -transitiva pero también incoativa-y a dormir -no incoativa pero también transitiva-. Y en los casos en que la diferencia de matiz entre la estructura pronominal y la intransitiva no pueda explicarse en términos aspectuales como, por ejemplo, en pasearse/pasear (alguien)-, el aspecto verbal será el mismo en los tres elementos triádicos -y carecerá por tanto, y lógicamente, de valor diferencial- y hablaremos de intransitividad/ transitividad, por un lado, y de presencia/ausencia del matiz en cuestión, por otro, para definir la oposición entre la estructura pronominal y, respectivamente, las formulaciones transitiva e intransitiva. En general, pues, las estructuras pronominales de este tipo habrán de considerarse al mismo tiempo medias y matizadoras del lexema verbal.

2.4. En el apartado introductorio de este trabajo hemos presentado nuestro modelo descriptivo de las estructuras pronominales en español, subrayando precisamente la unidad formal de dichas estructuras, con la presencia conjunta de un verbo en forma personal y un clítico reflejo. Dicho modelo, del que hemos dado cuenta -somera en algunos casos, y más detallada en otros- a lo largo del apartado, queda sintetizado en el cuadro de (1) (que 
reproducimos más abajo). A continuación nos hemos ocupado del tratamiento de la materia en la Nueva gramática de la lengua española, que no responde a una visión unitaria, sino parcelada en tres grandes categorías: la de las "estructuras" reflexivas y recíprocas, la de las pasivas e impersonales y la de los verbos pronominales. Respetando el criterio académico, irreprochable desde un punto de vista científico, creemos, sin embargo, que el nuestro -que no prejuzga sobre las diferencias de naturaleza entre las distintas estructurasresulta más didáctico. Al hilo del examen de los verbos pronominales en la Nueva gramática -dejando un poco al margen las otras dos categorías-, hemos llevado a cabo una comparación incipiente entre el modelo académico y el nuestro. Vamos a subrayar ahora los aspectos diferenciales de ambos.

Entre los verbos pronominales, según la Academia, estarían verbos como:

(18) Alegrarse, molestarse, ahogarse, hundirse, acercarse, levantarse, entrenarse, informarse;

arrepentirse, enterarse, jactarse; acordarse (de), aprovecharse (de), beneficiarse (de); irse, caerse, comerse (algo), leerse (algo), pagarse (algo), dejarse (algo).

Pues bien, desde el punto de vista de la definición dada de verbo pronominal (v. aquí, 2.3.2), este planteamiento es legítimo. Lo que ya no lo es tanto es que incluya todos lo verbos pronominales dentro de las construcciones medias, es decir, que identifique aquellos con estas, a reserva de los casos de construcción media no pronominal. Y ello por dos razones: 1) porque hay muchos verbos pronominales que no se ajustan a la definición de construcción media (2.3.2.) y 2) porque -salvo en el caso de los verbos pronominales inherentes (el segundo subgrupo de los citados en (18) ) - no se hace una distinción interna que a nosotros nos parece fundamental, en la medida al menos de que facilita enormemente el análisis; recordémosla: estructuras pronominales "regulares" (primer subgrupo de (18) ) / estructuras pronominales de incidencia léxica (resto de los subgrupos). En nuestro modelo descriptivo, las primeras -que se relacionan directamente con pasivas, impersonales, reflexivas y recíprocasson las únicas que se pueden considerar medias (y se definen en virtud de la intransitivación verbal, proceso verificable en la alternancia transitiva). Las segundas, que afectan directamente al lexema verbal, se subdividen en tres clases: 1) de verbo pronominal (subgrupo de arrepentirse), 2) de verbo cuasi-pronominal (subgrupo de acordarse de) y 3 ) matizadoras del lexema verbal (subgrupo de irse). Vamos a recordar al efecto el cuadro de (1), p. 79, ligeramente modificado: 


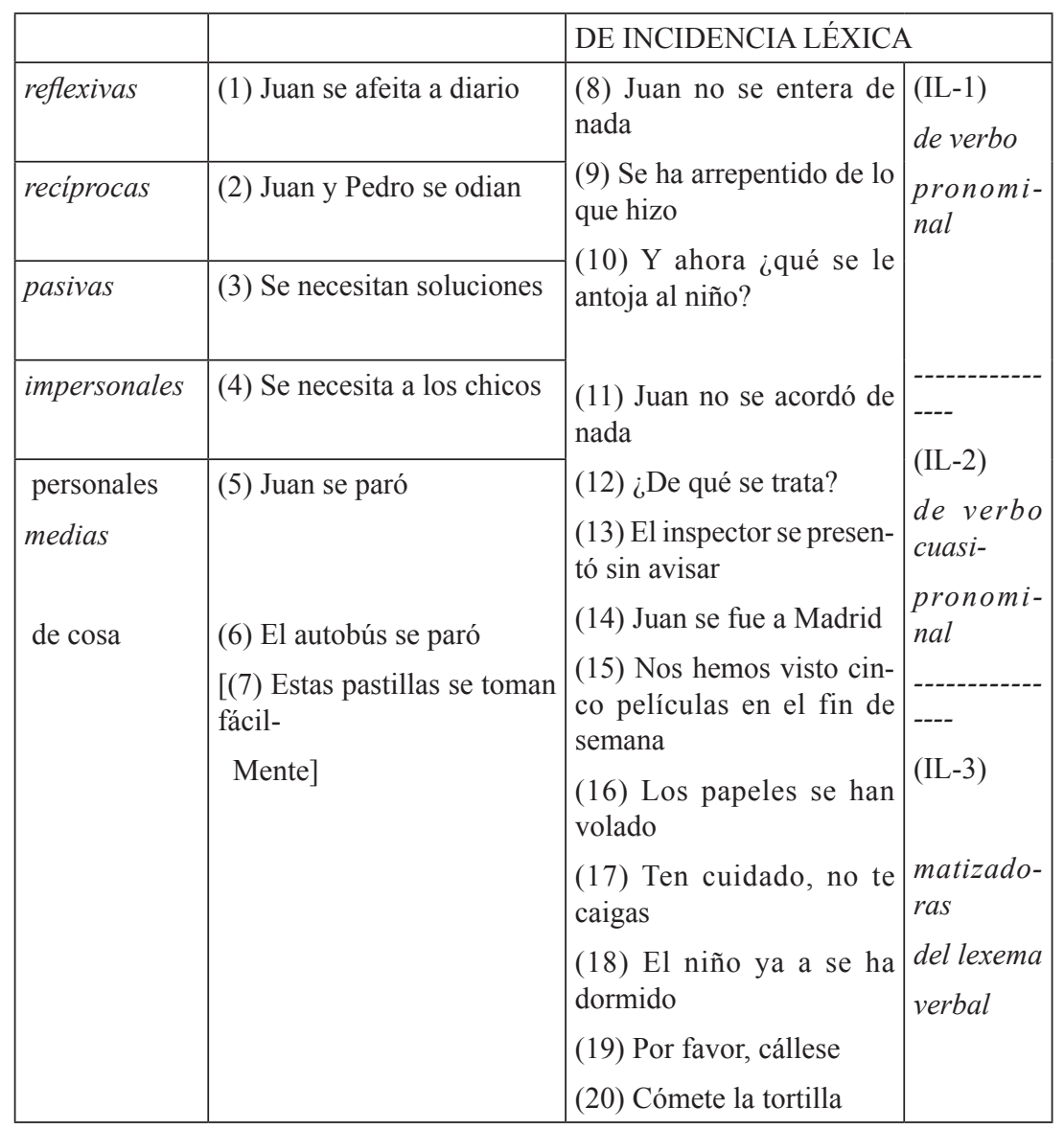

En suma, el planteamiento académico de la cuestión genera expectativas que no quedan precisamente satisfechas. Es ambicioso y no oculta los problemas, pero no aporta soluciones claras, con el agravante de que no lo reconoce explícita y suficientemente. Nos referimos en concreto al apartado dedicado a los verbos pronominales -porque el tratamiento de reflexivas, recíprocas, pasivas e impersonales nos parece altamente satisfactorio. No faltan, incluso en él, aciertos parciales, análisis precisos y apreciaciones llenas de sutileza y rigor gramatical (por no referirnos a las consideraciones históricas, de gran interés), pero el conjunto parece falto de rumbo, con un deambular incierto que no se sabe adónde va a parar. La doctrina académica, que debería ser una especie de "guía espiritual", mucho nos tememos que, en el caso que nos ocupa, está muy lejos de serlo. Por el contrario, creemos 
que nuestro planteamiento, resulta más didáctico, más abarcador, más claro, y da cuenta mejor de los hechos que tienen que ver con la 'pronominalidad'.

\section{REFERENCIAS BIBLIOGRÁFICAS}

Cartagena, Nelson. (1972). Sentido y estructura de las construcciones pronominales en español. Instituto Central de Lenguas de la Universidad de Concepción (Chile).

I. Bosque. (1985): "Sobre las construcciones recíprocas en español”, RSEL 15-1, pp. 5996.

J. R. Heredia. (2004). "Sobre el concepto de estructura pronominal media en español". En I. García Pinilla y Santiago Talavera Cuesta, coords., Charisterion Francisco Martín García oblatum. Cuenca, Ediciones de la Universidad de Castilla-La Mancha, pp. 633-659. (2009). "Las estructuras pronominales de incidencia léxica en español: bases para un diccionario multilingüe”. Studii şi Cercetări Filologice, 5, pp. 101-125.

(en prensa). "Apuntes contrastivos sobre estructuras pronominales de incidencia léxica: esp. encontrar(se) / rum. a (se) găsi, a (se) intâlni” [en Studii...].

J. R. Heredia et AL. (2002). "Las estructuras pronominales en español: proyecto de guía y análisis contrastivo". En M. D. Muñoz et al., eds., Actas del IV Congreso de Lingüística General. Cádiz, Universidad, III, pp. 1375-1386.

F. LÁzaro Mora. (1983). “Observaciones sobre 'se' medio”. En Serta Philologica F. Lázaro Carreter, I, Madrid: Cátedra, pp. 301-308.

M. A. Martín ZorraQuino. (1979). Las construcciones pronominales en español. Paradigma $y$ desviaciones. Madrid, Gredos.

M. Moliner. (1966). Diccionario de uso del español. Madrid, Gredos.

Real Academia Española. (2009). Nueva gramática de la lengua española. Madrid, Espasa Calpe. 